\title{
Amnion-derived stem cells: in quest of clinical applications
}

\author{
Toshio Miki*1,2
}

\begin{abstract}
In the promising field of regenerative medicine, human perinatal stem cells are of great interest as potential stem cells with clinical applications. Perinatal stem cells could be isolated from normally discarded human placentae, which are an ideal cell source in terms of availability, the fewer number of ethical concerns, less DNA damage, and so on. Numerous studies have demonstrated that some of the placenta-derived cells possess stem cell characteristics like pluripotent differentiation ability, particularly in amniotic epithelial (AE) cells. Term human amniotic epithelium contains a relatively large number of stem cell marker-positive cells as an adult stem cell source. In this review, we introduce a model theory of why so many AE cells possess stem cell characteristics. We also describe previous work concerning the therapeutic applications and discuss the pluripotency of the AE cells and potential pitfalls for amnion-derived stem cell research.
\end{abstract}

\section{Introduction}

The emerging field of regenerative medicine requires a reliable cell source in addition to biomaterial scaffolds and cytokine/growth factors. The 'cell' is a particularly critical element for cell replacement therapies in order to provide a safe and sufficient cell supply for clinical applications. Efforts to search for an adequate cell type and cell source have been conducted and have continued along with the discussions for their use in clinical application.

There are many potential cell sources for regenerative medicine, including bone marrow-derived mesenchymal stem cells, tissue-specific progenitor cells, embryonic

*Correspondence: toshiomi@usc.edu

${ }^{2}$ Department of Biochemistry and Molecular Biology, Eli and Edythe Broad Center for Regenerative Medicine and Stem Cell Research at USC University of Southern California, Keck School of Medicine, 1425 San Pablo Street, BCC 312, MC 9080,

Los Angeles, CA 90089, USA

Full list of author information is available at the end of the article stem (ES) cells, and induced pluripotent stem (iPS) cells. Although their biological potentials have been demonstrated, none of these cells is widely accepted as a definitive cell source for clinical applications. Each cell type possesses different advantages as well as limitations for their use, such as safety or availability. It will be helpful to search for a potential stem cell source from the perspective of its potential for clinical application. What is the sine qua non of the cells for clinically applicable regenerative medicine? At the end of this review, this question will be discussed further.

There is increasing evidence that the human placenta contains pluripotent or multipotent stem cells or both. Various multipotent stem cells have been isolated from different parts of the human placenta, such as the amnion, chorion, umbilical cord, and fetal blood. As placenta-derived cells, these stem cells have common advantages (Figure 1). Specific types of placenta-derived stem cells, such as trophoblastic, hematopoietic, and mesenchymal stroma cells, have been discussed elsewhere [1-3]. Here, we will review stem cells derived from the amnion of human placentae, specifically amniotic epithelial (AE) cells. First, we will summarize previous studies that have demonstrated the unique stem cell characteristics of AE cells. On the basis of these findings, we introduce a model theory that explains why some $\mathrm{AE}$ cells, unlike other adult somatic stem cells, may possess pluripotent features. Second, we will discuss topics and pitfalls that are currently under discussion. Third, previous works that are leading the therapeutic application of $\mathrm{AE}$ cells will be summarized. Last, the potential of the clinical application of AE-derived stem cells and the future direction of the research are discussed.

\section{Amniotic epithelial cells: what is so special about them?}

The epithelial cell population could be exclusively isolated from the amnions of term human placentae by specific enzymatic digestion [4]. The cell surface antigen profile data indicate that $\mathrm{AE}$ cells are basically homogeneous cell populations for most of the cell surface markers [5]; however, the reactivity against 'stem cell'specific antigens varies. Following isolation, some of the 
Human placenta is

- Readily available $\Rightarrow$ No disparity, Bio-Banking

- Normally discarded organ $\Rightarrow$ Fewer ethical concerns

- Neonatal tissue $\Longrightarrow$ Less environmental and age-acquired DNA damage

- Non-invasive procedure for the procurement $\Rightarrow$ Patients' QOL is high

Amniotic Epithelial cell is

-Abundant cells $\Rightarrow$ Sufficient for cell replacement therapies

- Relatively easy isolation procedure $\Rightarrow$ Cost- and effort-efficient

- Possess stem cell-like characteristics $\Rightarrow$ Wide-range application

- Possess immunomodulatory property $\Rightarrow$ Clinically applicable

- No tumorigenicity $\Rightarrow$ Safe

Figure 1. Advantages of amniotic epithelial cells for clinical application. Fundamental advantages of placenta-derived stem cells and amniotic epithelial cell-specific biological advantages are summarized. QOL, quality of life.

AE cells express stem cell surface markers, such as stagespecific embryonic antigen-3 (SSEA-3) and SSEA-4 and tumor rejection antigen 1-60 (TRA1-60) and TRA1-81, which are known to be expressed on human ES cells [6]. About $15 \%, 50 \%$, and $5 \%$ to $10 \%$ of naïve human $\mathrm{AE}$ (hAE) cells are positive for SSEA-3, SSEA-4, and TRA stem cell markers, respectively [7]. Normally, undifferentiated stem cells homogeneously express these stem cell markers [6]. The variance of the ratio of stem cell markerpositive cells indicates that naïve $\mathrm{AE}$ cell populations contain cells in various stage of 'stemness'. Interestingly, the ratios of stem cell marker-positive AE cells (5\% to $50 \%)$ are considerably higher than for other somatic/ tissue stem cells. Most of the somatic/tissue stem cells are $0.1 \%$ to $0.01 \%$ of the residing tissue. For instance, the hematopoietic stem cell population is only $0.01 \%$ to $0.05 \%$ of all bone marrow cells [8]. The relatively high ratio of stem cell marker-positive cells in $\mathrm{AE}$ cell populations as somatic stem cells could be explained by the model theory. The cell surface markers that are expressed by hAE cells are summarized and compared with the expression of other types of stem cells in Table 1 [2,7,9-15].

\section{Stem cells 'left behind': developmental uniqueness of the amniotic epithelial cell}

Unlike other parts of the placenta, the amniotic epithelium is a tissue of epiblastic origin. Human amnioblast is derived from the pluripotent epiblast around the eighth day following fertilization, whereas other parts of the placenta are derived from the trophectoderm. When the blastocyst is partially embedded in the endometrial stroma, the inner cell mass (or embryoblast) differentiates into two layers: the hypoblast and the epiblast. The epiblast is the source of all three germ layers and eventually forms the developing embryo. At the same time, a small cavity (amniotic cavity) appears within the epiblast. Epiblast cells adjacent to the amniotic cavity (Figure 2) are called amnioblasts, which eventually form the amniotic epithelium. Concomitantly, some of the migrating hypoblasts transdifferentiate into mesenchymal cells (extraembryonic mesoderm) and develop into the amniotic connective tissue. The epiblast-amnioblast segregation occurs before gastrulation, which is considered the first dynamic event of organogenesis. All short-range organogenetic signals may not reach the segregated stem cells throughout gestation. For instance, cardiogenesis is a complex event that is orchestrated by short-range fibroblast growth factors (FGFs) and Hedgehog signals [16]. Therefore, some epiblasts/amnioblasts that are spatially segregated by the amniotic cavity from the epicenter of organogenesis may escape from these differentiation cues. After 10 months, although most of the cells have differentiated by following the epithelial cell fate and have lost their stem cell characteristics, about $5 \%$ to $10 \%$ of the $\mathrm{AE}$ cells may retain the epiblastlike stem cell characteristics at term [7]. If this model theory is correct, fetal amniotic epithelium should contain more stem cell marker-positive cells than term amniotic epithelium. Izumi and colleagues [17] demonstrated that about $40 \%$ and $30 \%$ of fetal (early second trimester) AE cells are positive for stem cell markers TRA1-60 and TRA 1-81, respectively, whereas $5 \%$ of term AE cells are positive for these markers. The amnion is a fairly large tissue that may not be very uniform but is rather regionalized [18]. To exclude variances due to the 
Table 1. Comparison of stem cell surface marker expression in stem cells

\begin{tabular}{|c|c|c|c|c|c|c|c|c|c|c|c|c|}
\hline \multirow[b]{2}{*}{ First author } & \multicolumn{8}{|c|}{$\mathrm{AE}$} & \multirow{2}{*}{$\begin{array}{c}\text { ES } \\
\text { Osman }\end{array}$} & \multirow[t]{2}{*}{ NS } & \multirow[t]{2}{*}{ MS } & \multirow[t]{2}{*}{ HS } \\
\hline & Fatimah & Bilic & Stadler & Banas & Parolini & Minas & Ilancheran & Miki & & & & \\
\hline Reference & [9] & [10] & [11] & [12] & [2] & [13] & [14] & {$[5,7]$} & [15] & & & \\
\hline c-met & & & & + & & & & & & & + & \\
\hline CCR4 & & & & - & & & & \pm & + & & & \\
\hline CD10 & & & & & + & & & & & & + & \\
\hline CD105 & & & Up & & + & & & & & & + & \\
\hline CD106 (VCAM-1) & & & & & & & & - & & & + & \\
\hline CD117 (c-kit) & - & & & - & \pm & & & \pm & & & + & + \\
\hline CD13 & & & Up & & + & & & & & & + & \\
\hline CD14 & & & & & - & & & & & & & \\
\hline CD133 & & & & - & & & & - & + & + & + & + \\
\hline CD140b & & & & & + & & & & & & & \\
\hline CD166 (ALCAM) & & + & & & + & & & & & & + & \\
\hline CD24 & & & & + & & & & + & + & + & & \\
\hline CD29 & & & & + & + & & & & + & & + & \\
\hline CD31 (PECAM-1) & - & & & & & & & - & & & - & \\
\hline CD324 (E-cadherin) & & & & + & + & & & + & + & & & \\
\hline CD338 (ABCG2) & & & & + & & & & + & + & + & & + \\
\hline CD34 & - & - & & - & - & & & - & & & - & + \\
\hline CD349 & & & & & - & & & & & & & \\
\hline CD44 & + & + & Up & & + & & & & & & + & \\
\hline CD45 & - & - & & & - & & & & & & - & \\
\hline CD49d & & & & & - & & & & & & & \\
\hline CD49e & & + & Up & & + & & & & & & & \\
\hline CD49f & & & & + & & & & + & + & & & \\
\hline CD54 (ICAM-1) & & & + & & & & & + & & & + & \\
\hline CD73 & + & + & & & + & & & & & & + & \\
\hline CD9 & + & & & + & & & & + & + & + & & \\
\hline CD90 & + & & Up & Up & + & & + & & & & + & \\
\hline GCTM2 & & & & & + & + & & & + & & & \\
\hline Sialyl Lewis a & & & & & + & & & & & & & \\
\hline SSEA-1 & & & & - & - & & - & - & - & & & \\
\hline SSEA3 & & + & & + & + & & + & + & + & & & \\
\hline SSEA4 & & + & + & + & + & + & + & + & + & & & \\
\hline TRA1-60 & & & Down & + & + & & + & + & + & & & \\
\hline TRA1-81 & & & Down & + & + & & + & + & + & & & \\
\hline
\end{tabular}

-, negative; +, positive; \pm , weak; AE, amniotic epithelial cell; Down, downregulated each antigen expression; ES, embryonic stem cell; $\mathrm{HS}$, hematopoietic stem cell; MS, mesenchymal stem cell; NS, neural stem cell; SSEA, stage-specific embryonic antigen; TRA, tumor rejection antigen; Up, upregulated each antigen expression.

regionalized stem cell localization, amnion samples were harvested from three different parts of the amnion: the center of the disc, the edge of the disc, and the membrane part. There was no significant difference between samples by region, at least in these three parts [19]. On the other hand, the mechanism and signals that induce differentiation on $90 \%$ of amnioblasts of epiblast origin are unclear. It has been shown that cultured AE cells secrete various morphogens and growth factors such as epidermal growth factor, Noggin, Activin [20], platelet-derived growth factor, vascular endothelial growth factor, angiogenin, transforming growth factor-beta-2 (TGF- $\beta 2$ ), and tissue inhibitors of metalloproteinases (TIMP-1 and TIMP-2) [21]. In addition to playing an important role in 


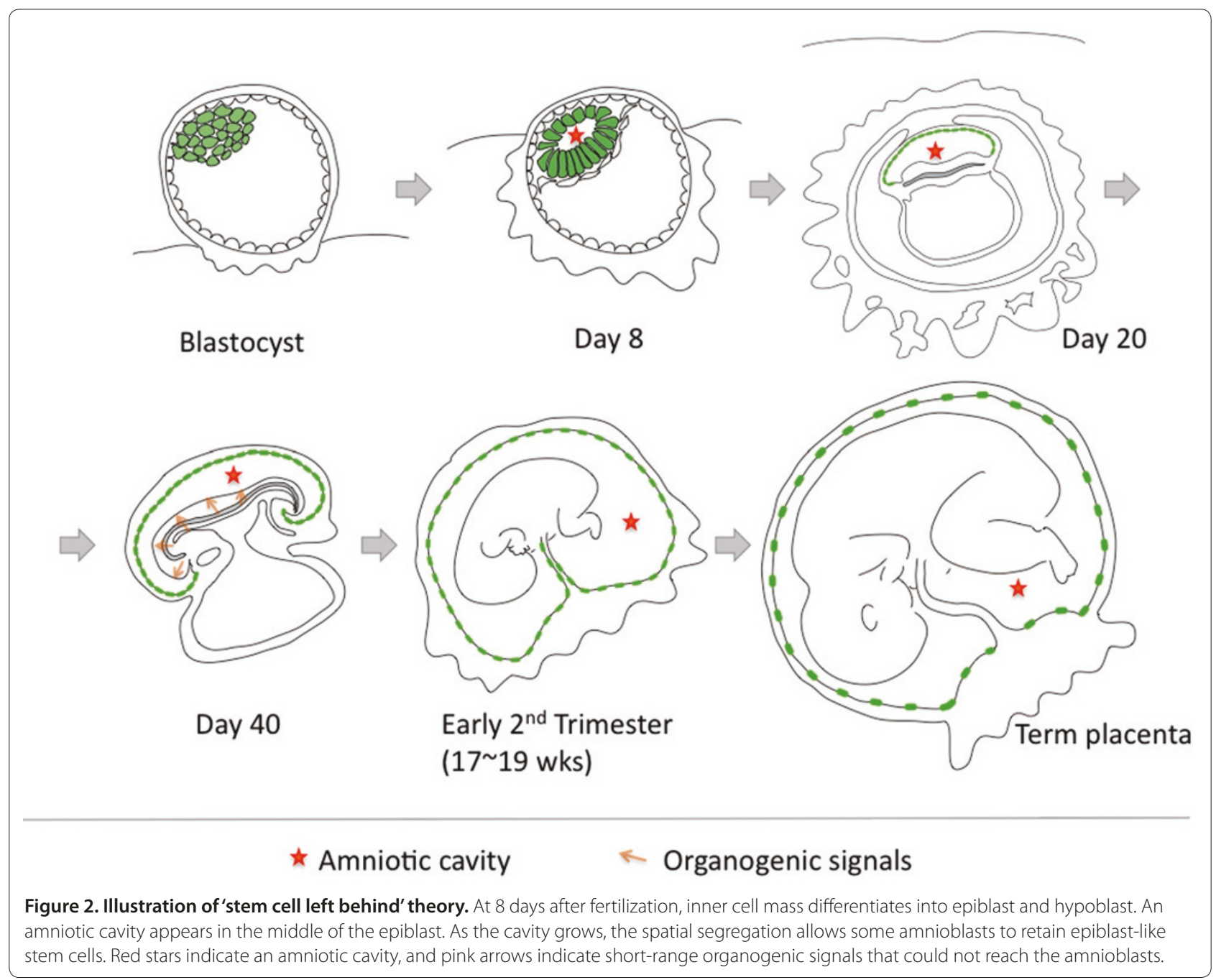

maintaining pregnancy, these factors may induce AE cell maturation or apoptosis to the epiblast-like immature AE cells. It must be noted that hAE cells are able to support the pluripotency of primate and mouse ES cells when primary hAE cells were used as feeder layer cells [22,23]. These data indicate that some of the secreted factors or cell-to-cell signaling (or both) might play a role in maintaining epiblast-like stemness of some AE cells. There are, however, no clear experimental data that indicate why the stem cell marker-positive AE cells unevenly differentiate even though all AE cells are exposed to the same environmental signals from the amniotic fluid. One of the possible mechanisms is 'lateral inhibition', which is a type of cell-to-cell interaction to regulate cell fate in the development of various cell types. This could be an interesting question for further investigation.

\section{Amniotic epithelial cells possess pluripotency?}

In addition to expressing stem cell-specific surface markers, AE cells express molecular markers of pluripotent stem cells: octamer-4 (OCT-4), NANOG, sex determining region Y-box 2 (SOX-2), Lefty-A, FGF-4, REX-1, and teratocarcinoma-derived growth factor 1 (TDGF-1) (cripto-1). Among those molecular stem cell markers, OCT-4 is known as one of the transcription factors that play a critical role in maintaining pluripotency and selfrenewal. OCT-4 belongs to the POU family of transcriptional regulators [24-26] and regulates the pluripotency of human and mouse ES cells [27]. Expression of OCT-4 is decreased along with the stem cell differentiation and the loss of expression leading to differentiation [28]. At the epiblast stage, OCT-4 continues to be expressed as long as cells remain undifferentiated [26]. The expression of OCT-4 is controlled epigenetically by hypermethylation of the enhancer/promoter region [29].

OCT-4 protein expression is observed in most AE cells. Some display nuclear-localized OCT-4, but for the majority of AE cells, the expression is cytoplasmic. There is concern over the OCT-4 expression in somatic cells [30]. OCT-4 exists as two splice variants: OCT-4A and 
OCT-4B [31]. Recent studies have suggested that it is the OCT-4A isoform that has the ability to confer and sustain pluripotency but that the OCT-4B may not be functional [32,33]. Lengner and colleagues [34] pointed out that published data describing positive results of OCT-4 expression in somatic stem cells might be erroneous because of investigator ignorance of the two isoforms. Primers or antibodies that recognize both isoforms might be misused to claim functional OCT-4 expression in some somatic stem cells. We have confirmed OCT-4A expression in naïve hAE cells by using a commercially available primer and probe set (Hs0300511_g1; Applied Biosystems, Foster City, CA, USA) that matches OCT4A-specific exons [17].

Although a number of investigations have provided evidence that suggests multipotency of AE cells, the pluripotency has not yet been proven. One of the critical issues is the difficulty to establish clonal expansion from a single AE cell, a step that is essential to demonstrate pluripotency in vitro. Unlike mouse ES cells, human ES cells and mouse epiblast-derived stem (EpiSC) cells are intolerant to passaging as single cells. Like EpiSC cells, AE cells do not maintain their stem cell characteristics well or survive as a single cell in culture. AE cells easily fall into the senescence state or differentiate into palmshaped epithelial cells when cultured at low density. The teratoma formation assay has been used as a gold standard assay to prove pluripotency of ES or iPS cells. However, this assay cannot be applied to evaluate AE cells. Because of the genetically stable characteristics, the AE cell does not form a teratoma when injected into immunodefficient mice $[7,14]$. The ultimate approach to determine pluripotency of AE-derived stem cells is generating chimeric animals. If an $\mathrm{AE}$ cell that is injected into the blastocyst will contribute to all germ layer cells in the resulting chimeric embryo, the pluripotency will be confirmed. In 2004, Tamagawa and colleagues [35] derived cell lines from human amnion and mixed them with mouse early embryonic stem cells to form an aggregation chimera. The authors succeeded in demonstrating that the human cells contributed to all three primordial germ layer formations in the xenogeneic chimera embryo [35]. Although the cell line cells are established from a mixed amniotic cell population that contains both AE cells and amniotic mesenchymal fibroblasts, this investigation suggested the pluripotency of the human amniotic cells. Further investigation will be required to clarify which cell population is responsible for the pluripotency.

\section{Multipotency of amniotic epithelial cells and the therapeutic potential}

Although the pluripotency of a single AE cell is not clarified yet, AE cells differentiate into cells of all three germ layers under appropriate culture conditions $[7,14]$. The changes of gene expression and cell morphology of $\mathrm{AE}$ cells in these experiments demonstrated the AE cell plasticity that is induced by exposure to exogenous growth factors or chemicals. At present, it has not been confirmed whether a single pluripotent amniotic stem cell differentiates into all three germ layers or whether there are various lineage-committed multipotent cells in the AE cell population. In spite of this critical question from a basic science point of view, it is a secondary concern from the perspective of clinical application. Since it is impossible to simultaneously induce the desired differentiation in $100 \%$ of the starting material of stem cells, some form of purification process is essential prior to using stem cell-derived therapeutic cells in clinical application. Therefore, the most important question from a clinical point of view is whether therapeutically useful cells can be produced from the hAE cell population. Here, we summarize previous works that suggest the differentiation potential of $\mathrm{AE}$ cells and the therapeutic potential tested in animal models.

It must be noted that there are developmental and anatomical differences between rodent and human amnion. Rodent amniotic epithelium is clearly derived from epiblasts; therefore, the usage of rodent AE cells as a model could be appropriate. However, owing to the size and anatomical uniqueness, the isolation of AE cells must be done very carefully. Recently, Dobreva and colleagues [36] focused on the species differences of the amnion and comprehensively reviewed this topic. This review is strongly recommended to researchers who plan to conduct research with rodent amnion stem cells, including amniotic fluid-derived stem cells.

\section{Ectoderm lineage}

Neurodegenerative diseases are among the most suitable target diseases for stem cell-based therapies. Since neurodegenerative diseases have many pathological processes in common, the cell transplantation approach could potentially ameliorate the symptoms of several distinct neurodegenerative diseases. There are two expected mechanisms of cell transplantation. One is the differentiation potential of the transplanted stem/ progenitor cells to neural cells. Sakuragawa's group [37], pioneers in $\mathrm{AE}$ research, demonstrated that cultured $\mathrm{AE}$ cells express markers of glial and neuronal progenitor cells. Our group confirmed that naïve hAE cells express various neural marker genes, including neuron-specific enolase, neurofilament-M, myelin basic protein, microtubule-associated protein 2 , and glial fibrillary acid protein [7]. Under appropriate culture conditions, AE cells express or upregulate neuron-specific gene expressions such as nestin and glutamic acid descarboxylase. Using the adenoviral labeling system, Ishii and colleagues 
[38] demonstrated that about $20 \%$ of hAE cells express oligodendrocyte marker genes, myelin basic protein, proteolipid protein, and 2,3'-cyclic nucleotide 3'-phosphodiesterase (CNPase). The neural differentiation capabilities of AE cells were confirmed by various researchers $[39,40]$. Amazingly, the capabilities were preserved even after long-term cryopreservation. Human amniocytes that were originally isolated in 1974 adopted neuronal morphology and expression of neural genes, including $\beta$ III-tublin, Gap-43, NF-M, TAU, and synaptophysin, after more than 30 years [41].

The other expectation of cell transplantation for neurodegenerative diseases is the ability to secrete functional or protective factors from the transplanted cells such as dopamine or some other factors, which result in protective/trophic effects or immunomodulatory effects $[42,43]$. For instance, in Parkinson's disease, there is a loss of the dopaminergic neural population in the substantia nigra [44]. In clinical settings, it has been shown that dopamine-producing tissue (fetal mesencephalic grafts) transplantation could ameliorate the symptoms [45]. hAE cells synthesize and release dopamine $[46,47]$. The dopamine synthesis responds to supplemented L-DOPA (L-3,4-dihydroxyphenylalanine) concentration in a dosedependent manner. Furthermore, transplanted AE cells might release neuroprotective factors or induce neurogenesis to improve diseased or damaged environments or both. It has been shown that hAE cells produce and secrete various types of trophic factors such as nerve growth factor, neurotrophin-3, and brain-derived neurotrophic factor [48-51].

This neural differentiation and neurotrophic potential of hAE cells has been tested in animal models. Transplanted hAE cells alleviated Parkinson-like symptoms in a dopamine-denervated rat model [52]. In these experiments, the engrafted hAE cells showed paracrine or neurotrophic effects rather than a contribution via neural differentiation. However, when rat AE cells were transplanted into ischemic hippocampus of adult gerbils, the rat AE-derived neuron-like cells were observed after 5 weeks of the transplantation [53]. The neural differentiation and the therapeutic effect of $\mathrm{AE}$ cells were also tested in a rat stroke model. The transplanted hAE cells migrated to the ischemic area and reduced infarct volume and improved behavioral function [54]. Recently, Suh [55] reported that hAE cell transplantation restored memory function in a transgenic mouse model of Alzheimer's disease. Although the mechanism is under investigation, these data encourage the clinical applications of the hAE cells for neurodegenerative diseases.

\section{Endoderm lineage}

Two cell types, hepatocytes and insulin-producing pancreatic cells, are most desired among the endoderm lineage cells. Both cells have been used for cell replacement therapies and their therapeutic concept and efficiency have been shown [56-59]. The insufficient supply of human hepatocytes or beta cells, however, is one of the reasons that prevent these promising therapies from becoming standard clinical applications. Thus, safe and constant supplies of these functional cells are urgently required. In addition, stem cell-derived hepatocytes will be useful not only for cell replacement therapy (hepatocyte transplantation) [57] but also for toxicology and drug development [60].

Sakuragawa and colleagues [61] reported that cultured hAE cells expressed and produced albumin and $\alpha$-fetoprotein in vitro and in vivo. The hepatic characteristics of hAE cells were extensively investigated by Takashima and colleagues [62]. Our group applied a step-wise exogenous growth factor stimulation protocol to induce further hepatic maturation in hAE cells [63]. The AE-derived hepatocyte-like cells expressed late-phase hepatic differentiation markers, including various inducible cytohrome P450 genes, which are essential for drug metabolism as functional hepatocytes. These cells were also transplanted into immunodeficient mice, and human $\alpha-1$ antitrypsin was detected circulating in the serum of recipient mice, and this confirmed that the engrafted hAE cells function as hepatocytes in mouse liver. Recently, Manuelpillai and colleagues [64] transplanted hAE cells into drug-induced cirrhosis model animals and demonstrated the anti-fibrosis effect of hAE cells. The data indicate that the therapeutic effect of transplanted hAE cells is more likely the immunomodulatory effect by suppressing inflammatory activation of hepatic stellate cells. On the other hand, the authors demonstrated human albumin in mouse sera that might be secreted from differentiated hAE-derived hepatic cells. Rat amniotic cells have been isolated and used to simulate allogeneic cell transplantation [65-67]. The transplanted rat $\mathrm{AE}$ cells survived in the liver following allogeneic transplantation for at least 30 days [65]. Although the rodent amniotic cell property might be different from that of humans, the therapeutic efficiency of $\mathrm{AE}$ cells, together with the basal advantages of the placenta-derived stem cells, suggests a treatment option for liver diseases.

Several groups demonstrated the pancreatic differentiation potential of hAE cells $[7,68,69]$. Under appropriate culture conditions, pancreatic cell-related genes such as $P D X-1, P A X-6, N K X 2.2$, insulin, and glucagon were upregulated in vitro [7]. The therapeutic potential was also demonstrated by the transplantation of cultured hAE cells in the spleen of diabetic mice. The serum glucose levels were normalized for several months after the transplant, suggesting that the transplanted AE cells differentiated into insulin-producing beta cells [68]. This finding was later confirmed with comprehensive analyses 
that demonstrated glucose-responsive c-peptide production [69]. In vitro differentiation and involvement of histamine nicotinamide-induced pancreatic differentiation were further investigated [70].

In addition to the hepatic and pancreatic differentiation, the capability of AE cells differentiating into other types of endoderm lineage cells has been reported. Moodley and colleagues [71] demonstrated that naïve human amnion epithelial cells differentiate into lung epithelium (type II pneumocyte) 2 weeks after parenteral injection into a bleomycin-induced lung injury SCID (severe combined immunodeficiency) mice model. The transplanted hAE cells reduced inflammation and abrogated fibrosis post-lung injury. Moritoki and colleagues [72] systemically transplanted EGFP (enhanced green fluorescent protein)-transgenic mice $\mathrm{AE}$ cells into chemically induced cholestasis mouse model animals. The EGFP and cholangiocyte marker CK7 doublepositive cells formed a bile duct-like tubular structure in the chronic cholestatic mouse liver.

\section{Mesoderm lineage}

Because adult cardiomyocytes do not regenerate sufficiently, there is great interest in finding suitable cell sources for cellular cardiomyoplasty. hAE cells also possess the potential to differentiate into cardiac cells [7]. Although AE-derived cardiomyocyte-like cells expressed cardiac differentiation marker genes, immunocytochemistry analysis showed that the expression pattern of $\alpha$-actinin was similar to that of immature cardiomyocytes. The therapeutic potential was demonstrated by using rat amniotic cells and a rat acute infarction model [73]. Although transplanted rat amniotic cells dramatically improved the cardiac function, only a few transplanted cells were differentiated into cardiomyocytes ( $\alpha$-actininpositive cells). The therapeutic effect was speculated to be due to paracrine or immunomodulatory effects of the rat amniotic cells. An interesting application of amniotic membrane was tested, and the therapeutic efficiency was demonstrated. Cargnoni and colleagues [74] applied a fragment of human amniotic membrane as a cardiac patch on an infarction area of a rat heart. The postischemic cardiac function was significantly improved with the amnion patch. This investigation importantly demonstrated that secondary cardiac ischemic injury could be prevented by humoral factors that are released from the amnion. Recently, functional cardiac differentiation of human amniotic cells was demonstrated [75]. The cardiomyogenic differentiation was induced by a co-culture system with murine fetal cardiomyocytes. The structure of sarcomeric $\alpha$-actinin and the spontaneous beating and in vivo contribution of human amnion-derived cardiomyocytes were demonstrated. Stem cell-derived cardiomyocytes are also expected to be an important new tool for drug development [60]. The in vitro functional hAE-derived cardiomyocytes could be a cell source for these assays. Further investigation for culture condition optimization or direct reprogramming will be required along with a definition of selection markers of functional mature cardiomyocytes. The studies that demonstrate the differentiation capability of AE cells into all three germ layer lineages are summarized in Table 2.

\section{Advantages of human amniotic epithelial cells for clinical applications}

From the view of clinicians and patients, the sine qua non of clinically applicable stem cells is first, 'safety'; second, 'therapeutic efficiency'; and, last, 'availability/sufficient quantity'. Several types of stem cells could serve as cell sources for cellular therapy. Generally, stem cells are classified according to their differentiation ability and origin. Pluripotent stem cells, such as ES cells and iPS cells, are considered to be the most promising stem cells because of their tremendous differentiation ability. The 'safety', however, is always a concern. The pluripotency comes with genetical instability, which leads to concerns for tumorigenicity. Although the 'therapeutic efficiency' is promised, the long-term efficiency has not yet been proven. Furthermore, the expansion and maintenance to obtain a therapeutically sufficient number of cells require time, effort, and cost.

Adult stem cells can be derived from virtually any tissue or organ. Most adult stem cells are tissue-specific lineage-committed multipotent cells. Some adult stem cells such as mesenchymal stem cells and hematopoietic stem cells are already applied in clinics and showed therapeutic efficiency, mainly with their immunomodulatory property. Therefore, the clinical applications are considerably safe, particularly in the case of autologous transplantation.

A similar immunomodulatory property has been demonstrated with hAE cells [76-80]. hAE cells inhibited allogeneic mixed lymphocyte reactions in a dosedependent manner with $66 \%$ to $93 \%$ inhibition [81]. Most of the report demonstrated the immunomodulatory effect by secretion of suppressive mediators such as TNF$\alpha$, FasL, TRAIL, TGF- $\beta$, and MIF. On the other hand, Banas and colleagues [12] demonstrated that the immunomodulatory effect of AE cells is dependent on cell-to-cell contact with responding $\mathrm{T}$ cells. By using non-serum culture conditions, the authors demonstrated that hAE cells inhibit peripheral blood mononuclear cell proliferative responses to mitogen, alloantigen, and recall antigen but preactivated $\mathrm{T}$-cell blast response. The results suggested that the presence of HLA-G immunological cell surface molecules is responsible for the cell-to-cell immunosuppressive properties of AE cells. In addition to 
Table 2. Differentiation potential of amniotic epithelial cells

\begin{tabular}{|c|c|c|c|c|}
\hline Lineage & Cell type & Species & First author & Reference \\
\hline \multirow[t]{8}{*}{ Ectoderm } & Neural progenitor cell & Human & Sakuragawa & {$[37]$} \\
\hline & Dopamine-producing cell & Human & Kakishita & {$[47,52]$} \\
\hline & Neural cell & Human & Miki & [7] \\
\hline & Oligodendrocyte & Human & Ishii & {$[38]$} \\
\hline & Neural cell & Human & Niknejad & {$[40]$} \\
\hline & Neural cell & Human & Woodbury & [41] \\
\hline & Neuronal & Rat & Okawa & [53] \\
\hline & Neural & Rat & Marcus & {$[67]$} \\
\hline \multirow[t]{6}{*}{ Mesoderm } & Adipogenic & Human & Ilancheran & [14] \\
\hline & Chondrogenic & Human & Ilancheran & [14] \\
\hline & Osteogenic & Human & Stadler & [11] \\
\hline & Cardiomyogenic & Human & Miki & [7] \\
\hline & Cardiomyogenic & Human & Tsuji & {$[75]$} \\
\hline & Cardiomyogenic & Rat & Fujimoto & [73] \\
\hline \multirow[t]{13}{*}{ Endoderm } & Hepatic & Human & Miki & {$[7,63]$} \\
\hline & Hepatic & Human & Sakuragawa & {$[61]$} \\
\hline & Hepatic & Human & Takashima & {$[62]$} \\
\hline & Hepatic & Human & Manuelpillai & [64] \\
\hline & Hepatic & Rat & Nakajima & {$[65]$} \\
\hline & Hepatic & Rat & Takahashi & [66] \\
\hline & Hepatic & Rat & Marcus & {$[67]$} \\
\hline & Insulin-producing cell & Human & Miki & [7] \\
\hline & Insulin-producing cell & Human & Wei & [68] \\
\hline & Insulin-producing cell & Human & Hou & [69] \\
\hline & Insulin-producing cell & Human & Szukiewicz & [70] \\
\hline & Bile duct & Mouse & Moritoki & [72] \\
\hline & Pneumocyte & Human & Moodley & [71] \\
\hline
\end{tabular}

the HLA-G expression [82-84], the expressions of complement inhibitory proteins, CD59 antigen, decayaccelerating factor, membrane attack complex, and Fas antigen/CD95/APO1 have been reported as potential immunoregulatory factors from hAE cells [85-88]. Nevertheless, further investigation is required to fully elucidate the underlying mechanisms of the immunomodulatory effect of hAE cells.

Importantly, the safety of AE upon transplantation has been shown in a clinical setting. hAE cells have been used in clinics to correct lysosomal storage disease [89-91]. Although the applications were not conducted as a stem cell therapy, more than 50 cases of AE cell/tissue transplantations have been performed in various institutes [90-92]. No tumor formation has been reported from these clinical trials. As it has been described, AE cells are clearly non-tumorigenic when transplanted into immunodeficient animals $[7,14]$. A total of one to two million hAE cells was injected into more than 50 individual mice, which were observed for a maximum of 516 days. None of the AE cell transplants has led to the development of tumors by any route of administration in SCID-beige mice or Rag-2 knockout mice. In parallel, cytogenetic analysis confirmed genetical stability of cultured AE cells [7]. AE cells do not express telomerase reverse transcriptase (TERT) mRNA [7]. A study demonstrated that immortalized cells by expression of TERT could exhibit some neoplastic transformation toward what seem to be cancer stem cells [93]. Missing TERT expression may be a safety advantage. Since more than 100 million cells can be isolated from one placenta, long-term culture and massive replication are not required to use AE cells as a cell source. For instance, only half a million cells will be sufficient to improve the devastating symptoms of Parkinson's disease and Huntington's disease [94,95]. Furthermore, human placenta is a neonatal tissue that has less age-acquired and environmental DNA damage. Naturally, the neonatal cells should possess a life-long 
viability. Given these facts, the AE cell is clearly a safe cell for clinical application.

A placenta is discarded after every live birth; objections to derive stem cells from placentae are not expected. Isolating and using stem cells from discarded human tissue are ultimate recycling biotechnologies, which would be acceptable in today's society. Human placenta is readily available tissue wherever human society exists. Therefore, there will be no regional disparities for placenta-derived stem cell therapies. Current statistics indicate that there are over 4 million births and over 1 million cesarean sections performed in the US every year. The sheer volume of available placenta tissue leads us to the idea of establishing a biobank system for placentaderived stem cells. Nakatsuji and colleagues [96] estimated that a cell bank with only 30 stem cell lines could match the HLA-A, HLA-B, and HLA-DR haplotypes in $82.2 \%$ of the Japanese population. On the basis of these estimations and the theoretical number of available placentae, it is clearly feasible to establish a biobank that stores human placenta-derived stem cells with all HLA haplotypes. Clinically relevant stem cells should be easily and reproducibly cultured and manipulated. The AE cell isolation procedure is relatively easy and does not require a special laboratory set-up [4]. The biobanking system therefore could be established in any country and connected as a network to provide all HLA types, including race dominant types.

Ethical issues surrounding both embryonic and fetal stem cells do not apply to the use of discarded human placentae. However, once the therapeutic efficiency of placenta-derived stem cells is demonstrated, this normally discarded medical waste may turn into valuable property. The cell-acquiring process, cost, and proprietary rights will be new ethical issues. A regulatorycompliant system will be required for cell-acquiring and -providing processes. The precedent and current regulations for the umbilical cord blood cell usage could be useful to prepare a guideline for procurements of placenta-derived stem cells [97].

The use of this ideal stem cell could take one of two directions in future clinical regenerative medicine. One direction will be in developing technology to derive pluripotent stem cell lines from AE cells, which possess a biological potential equivalent to that of ES cells and iPS cells. This direction, however, may eliminate the AE cell advantage that is discussed here. The other direction is to aim directly at differentiation to obtain functional target cells. The stem cell-derived cell therapy requires a selection step prior to the cell application to patients to ensure safety and efficiency. The genetic stability and non-tumorigenicity of AE cells will be the advantage for this approach. Unlike in ES cells or iPS cells, leakage concerns at the selection step will not be a critical issue.

\section{Conclusions}

Herein, we reviewed the stem cell characteristics of amnion cells, especially AE cells. We introduced a model theory that may explain why so many cells with stem cell features are present in the amnion. The model theory has been proposed by several research teams, including ours $[5,7,14,34]$. Previous studies that demonstrate the differentiation and therapeutic potential of AE cells were summarized. We described four major reasons why placentaderived cells are a significant cell source for clinical applications. The AE cell meets two important conditions that are required for clinically relevant stem cells: safety and availability. So far, no stem cells are able to differentiate into therapeutically useful cell types in vitro, or their differentiation is not well controlled. As with other types of stem cells, further investigations will be required to induce $\mathrm{AE}$ cells to differentiate into therapeutically useful cells. Since AE cells are extremely safe and show therapeutic efficiency in animal models, clinical application should be considered in the near future.

\section{Abbreviations}

AE, amniotic epithelial; EGFP, enhanced green fluorescent protein; EpiSC, epiblast-derived stem; ES, embryonic stem; FGF, fibroblast growth factor; hAE, human amniotic epithelial; HLA, human leukocyte antigen; iPS, induced pluripotent stem; OCT-4, octamer-4; SCID, severe combined immunodeficiency; SSEA, stage-specific embryonic antigen; TERT, telomerase reverse transcriptase; TRA, tumor rejection antigen.

\section{Competing interests}

The author owns stock in Stemnion, Inc. (Pittsburgh, PA, USA). He has received no payment for the preparation of this manuscript and declares that he has no other competing interests.

\section{Acknowledgments}

The author would like to thank Claudia A Huggins for her assistance in preparing the manuscript.

\section{Author details}

'Department of Developmental Biology, University of Pittsburgh, 530 45th Street, 8112 Rangos Research Center, Pittsburgh, PA 15201, USA. ${ }^{2}$ Current affiliation: Department of Biochemistry and Molecular Biology, Eli and Edythe Broad Center for Regenerative Medicine and Stem Cell Research at USC University of Southern California, Keck School of Medicine, 1425 San Pablo Street, BCC 312, MC 9080, Los Angeles, CA 90089, USA.

Published: 19 May 2011

\section{References}

1. Fauza D: Amniotic fluid and placental stem cells. Best Pract Res Clin Obstet Gynaecol 2004, 18:877-891.

2. Parolini $O$, Alviano F, Bagnara GP, Bilic G, Bühring HJ, Evangelista M, Hennerbichler S, Liu B, Magatti M, Mao N, Miki T, Marongiu F, Nakajima H, Nikaido T, Portmann-Lanz CB, Sankar V, Soncini M, Stadler G, Surbek D, Takahashi TA, Redl H, Sakuragawa N, Wolbank S, Zeisberger S, Zisch A, Strom SC: Concise review: isolation and characterization of cells from human term placenta: outcome of the first international workshop on placenta derived stem cells. Stem Cells 2008, 26:300-311.

3. Pozzobon M, Ghionzoli M, De Coppi P: ES, iPS, MSC, and AFS cells. Stem cells exploitation for Pediatric Surgery: current research and perspective. Pediatr Surg Int 2010, 26:3-10.

4. Miki T, Marongiu F, Dorko K, Ellis EC, Strom SC: Isolation of amniotic epithelial stem cells. Curr Protoc Stem Cell Bio/ 2010, Chapter 1:Unit 1E 3.

5. Miki T, Strom SC: Amnion-derived pluripotent/multipotent stem cells. Stem Cell Rev 2006, 2:133-142. 
6. Henderson JK, Draper JS, Baillie HS, Fishel S, Thomson JA, Moore H, Andrews PW: Preimplantation human embryos and embryonic stem cells show comparable expression of stage-specific embryonic antigens. Stem Cells 2002, 20:329-337.

7. Miki T, Lehmann T, Cai H, Stolz DB, Strom SC: Stem cell characteristics of amniotic epithelial cells. Stem Cells 2005, 23:1549-1559.

8. Lagasse E, Connors H, Al-Dhalimy M, Reitsma M, Dohse M, Osborne L, Wang X Finegold M, Weissman IL, Grompe M: Purified hematopoietic stem cells can differentiate into hepatocytes in vivo. Nat Med 2000, 6:1229-1234.

9. Fatimah SS, Ng SL, Chua KH, Hayati AR, Tan AE, Tan GC: Value of human amniotic epithelial cells in tissue engineering for cornea. Hum Cell 2010, 23:141-151.

10. Bilic G, Zeisberger SM, Mallik AS, Zimmermann R, Zisch AH: Comparative characterization of cultured human term amnion epithelial and mesenchymal stromal cells for application in cell therapy. Cell Transplant 2008, 17:955-968.

11. Stadler G, Hennerbichler S, Lindenmair A, Peterbauer A, Hofer K, van Griensven M, Gabriel C, Redl H, Wolbank S: Phenotypic shift of human amniotic epithelial cells in culture is associated with reduced osteogenic differentiation in vitro. Cytotherapy 2008, 10:743-752.

12. Banas RA, Trumpower C, Bentlejewski C, Marshall V, Sing G, Zeevi A: Immunogenicity and immunomodulatory effects of amnion-derived multipotent progenitor cells. Hum Immuno/ 2008, 69:321-328.

13. Minas V, Mylonas I, SchiessI B, Mayr D, Schulze S, Friese K, Jeschke U, Makrigiannakis A: Expression of the blood-group-related antigens Sialyl Lewis a, Sialyl Lewis $x$ and Lewis $y$ in term placentas of normal, preeclampsia, IUGR- and HELLP-complicated pregnancies. Histochem Cell Biol 2007, 128:55-63.

14. Ilancheran S, Michalska A, Peh G, Wallace EM, Pera M, Manuelpillai U: Stem cells derived from human fetal membranes display multilineage differentiation potential. Biol Reprod 2007, 77:577-588.

15. Osman I, Crawford M, Jordan F, Young A, Norman J, Thomson A: Expression and localization of cell adhesion molecules in human fetal membranes during parturition. J Reprod Immuno/ 2004, 63:11-21.

16. Lavine KJ, Ornitz DM: Fibroblast growth factors and Hedgehogs: at the heart of the epicardial signaling center. Trends Genet 2008, 24:33-40.

17. Izumi M, Pazin BJ, Minervini CF, Gerlach J, Ross MA, Stolz DB, Turner ME, Thompson RL, Miki T: Quantitative comparison of stem cell marker-positive cells in fetal and term human amnion. J Reprod Immuno/ 2009, 81:39-43.

18. Han YM, Romero R, Kim JS, Tarca AL, Kim SK, Draghici S, Kusanovic JP, Gotsch F, Mittal P, Hassan SS, Kim CJ: Region-specific gene expression profiling: novel evidence for biological heterogeneity of the human amnion. Biol Reprod 2008, 79:954-961.

19. Miki T, Mitamura K, Ross MA, Stolz DB, Strom SC: Identification of stem cell marker-positive cells by immunofluorescence in term human amnion. J Reprod Immuno/ 2007, 75:91-96.

20. Koyano S, Fukui A, Uchida S, Yamada K, Asashima M, Sakuragawa N: Synthesis and release of activin and noggin by cultured human amniotic epithelial cells. Dev Growth Differ 2002, 44:103-112.

21. Uberti MG, Pierpont YN, Ko F, Wright TE, Smith CA, Cruse CW, Robson MC, Payne WG: Amnion-derived cellular cytokine solution (ACCS) promotes migration of keratinocytes and fibroblasts. Ann Plast Surg 2010, 64:632-635.

22. Miyamoto K, Hayashi K, Suzuki T, Ichihara S, Yamada T, Kano Y, Yamabe T, Ito Y: Human placenta feeder layers support undifferentiated growth of primate embryonic stem cells. Stem Cells 2004, 22:433-440.

23. Lai D, Cheng W, Liu T, Jiang L, Huang Q: Use of human amnion epithelial cells as a feeder layer to support undifferentiated growth of mouse embryonic stem cells. Cloning Stem Cells 2009, 11:331-340.

24. Scholer HR, Dressler GR, Balling R, Rohdewohld H, Gruss P: Oct-4: a germlinespecific transcription factor mapping to the mouse t-complex. EMBO J 1990, 9:2185-2195.

25. Rosner MH, Vigano MA, Ozato K, Timmons PM, Poirier F, Rigby PW, Staudt LM: A POU-domain transcription factor in early stem cells and germ cells of the mammalian embryo. Nature 1990, 345:686-692.

26. Pesce $M$, Wang $X$, Wolgemuth DJ, Scholer H: Differential expression of the Oct-4 transcription factor during mouse germ cell differentiation. Mech Dev 1998, 71:89-98.

27. Pesce $M$, Scholer HR: Oct-4: gatekeeper in the beginnings of mammalian development. Stem Cells 2001, 19:271-278.

28. Niwa H: Molecular mechanism to maintain stem cell renewal of ES cells. Cell Struct Funct 2001, 26:137-148.
29. Hattori N, Nishino K, Ko YG, Hattori N, Ohgane J, Tanaka S, Shiota K: Epigenetic control of mouse Oct-4 gene expression in embryonic stem cells and trophoblast stem cells. J Bio/ Chem 2004, 279:17063-17069.

30. Liedtke S, Stephan M, Kogler G: Oct4 expression revisited: potential pitfalls for data misinterpretation in stem cell research. Biol Chem 2008, 389:845-850.

31. Takeda J, Seino S, Bell Gl: Human Oct3 gene family: cDNA sequences, alternative splicing, gene organization, chromosomal location, and expression at low levels in adult tissues. Nucleic Acids Res 1992, 20:4613-4620

32. Cauffman G, Liebaers I, Van Steirteghem A, Van de Velde H: POU5F1 isoforms show different expression patterns in human embryonic stem cells and preimplantation embryos. Stem Cells 2006, 24:2685-2691.

33. Lee J, Kim HK, Rho JY, Han YM, Kim J: The human OCT-4 isoforms differ in their ability to confer self-renewal. J Bio/ Chem 2006, 281:33554-33565.

34. Lengner CJ, Camargo FD, Hochedlinger K, Welstead GG, Zaidi S, Gokhale S, Scholer HR, Tomilin A, Jaenisch R: Oct4 expression is not required for mouse somatic stem cell self-renewal. Cell Stem Cell 2007, 1:403-415.

35. Tamagawa T, Ishiwata I, Saito S: Establishment and characterization of a pluripotent stem cell line derived from human amniotic membranes and initiation of germ layers in vitro. Hum Cell 2004, 17:125-130.

36. Dobreva MP, Pereira PN, Deprest J, Zwijsen A: On the origin of amniotic stem cells: of mice and men. Int J Dev Biol 2010, 54:761-777.

37. Sakuragawa $N$, Thangavel R, Mizuguchi M, Hirasawa M, Kamo I: Expression of markers for both neuronal and glial cells in human amniotic epithelial cells. Neurosci Lett 1996, 209:9-12.

38. Ishii T, Ohsugi K, Nakamura S, Sato K, Hashimoto M, Mikoshiba K, Sakuragawa N: Gene expression of oligodendrocyte markers in human amniotic epithelial cells using neural cell-type-specific expression system. Neurosci Lett 1999, 268:131-134

39. Marcus AJ, Coyne TM, Black IB, Woodbury D: Fate of amnion-derived stem cells transplanted to the fetal rat brain: migration, survival and differentiation. J Cell Mol Med 2008, 12:1256-1264.

40. Niknejad H, Peirovi H, Ahmadiani A, Ghanavi J, Jorjani M: Differentiation factors that influence neuronal markers expression in vitro from human amniotic epithelial cells. Eur Cell Mater 2010, 19:22-29.

41. Woodbury D, Kramer BC, Reynolds K, Marcus AJ, Coyne TM, Black IB: Long-term cryopreserved amniocytes retain proliferative capacity and differentiate to ectodermal and mesodermal derivatives in vitro. Mol Reprod Dev 2006, 73:1463-1472.

42. Orlacchio A, Bernardi G, Martino S: Stem cells: an overview of the current status of therapies for central and peripheral nervous system diseases. Curr Med Chem 2010, 17:595-608

43. Kim SU, de Vellis J: Stem cell-based cell therapy in neurological diseases: a review. J Neurosci Res 2009, 87:2183-2200.

44. Arenas E: Towards stem cell replacement therapies for Parkinson's disease. Biochem Biophys Res Commun 2010, 396:152-156.

45. Clarkson ED: Fetal tissue transplantation for patients with Parkinson's disease: a database of published clinical results. Drugs Aging 2001, 18:773-785.

46. Elwan MA: Synthesis of dopamine from L-3,4-dihydroxyphenylalanine by human amniotic epithelial cells. Eur J Pharmacol 1998, 354:R1-2.

47. Kakishita K, Elwan MA, Nakao N, Itakura T, Sakuragawa N: Human amniotic epithelial cells produce dopamine and survive after implantation into the striatum of a rat model of Parkinson's disease: a potential source of donor for transplantation therapy. Exp Neuro/ 2000, 165:27-34.

48. Uchida S, Inanaga Y, Kobayashi M, Hurukawa S, Araie M, Sakuragawa N: Neurotrophic function of conditioned medium from human amniotic epithelial cells. J Neurosci Res 2000, 62:585-590.

49. Uchida S, Suzuki Y, Araie M, Kashiwagi K, Otori Y, Sakuragawa N: Factors secreted by human amniotic epithelial cells promote the survival of rat retinal ganglion cells. Neurosci Lett 2003, 341:1-4.

50. Meng XT, Chen D, Dong ZY, Liu JM: Enhanced neural differentiation of neural stem cells and neurite growth by amniotic epithelial cell co-culture. Cell Biol Int 2007, 31:691-698.

51. Meng XT, Li C, Dong ZY, Liu JM, LiW, Liu Y, Xue H, Chen D: Co-transplantation of bFGF-expressing amniotic epithelial cells and neural stem cells promotes functional recovery in spinal cord-injured rats. Cell Biol Int 2008, 32:1546-1558.

52. Kakishita K, Nakao N, Sakuragawa N, Itakura T: Implantation of human amniotic epithelial cells prevents the degeneration of nigral dopamine neurons in rats with 6-hydroxydopamine lesions. Brain Res 2003, 980:48-56.

53. Okawa H, Okuda O, Arai H, Sakuragawa N, Sato K: Amniotic epithelial cells transform into neuron-like cells in the ischemic brain. Neuroreport 2001, 
$12: 4003-4007$

54. Liu T, Wu J, Huang Q, Hou Y, Jiang Z, Zang S, Guo L: Human amniotic epithelial cells ameliorate behavioral dysfunction and reduce infarct size in the rat middle cerebral artery occlusion model. Shock 2008, 29:603-611.

55. Suh YH: Peripheral Stem Cell Therapy for Alzheimer's Disease. Paper presented at: 4th Annual Symposium on Regenerative Medicine and Adult Stem Cell Research; 2010; Kyoto, Japan.

56. Fox IJ, Roy-Chowdhury J: Hepatocyte transplantation. J Hepatol 2004, 40:878-886

57. Strom SC, Bruzzone P, Cai H, Ellis E, Lehmann T, Mitamura K, Miki T: Hepatocyte transplantation: clinical experience and potential for future use. Cell Transplant 2006, 15 Suppl 1:S105-110.

58. Hayek A: Cell replacement in type 1 diabetes mellitus. J Pediatr Endocrinol Metab 2005, 18 Suppl 1:1157-1161

59. Calne R: Cell transplantation for diabetes. Philos Trans R Soc Lond B Biol Sci 2005, 360:1769-1774.

60. Davila JC, Cezar GG, Thiede M, Strom S, Miki T, Trosko J: Use and application of stem cells in toxicology. Toxicol Sci 2004, 79:214-223.

61. Sakuragawa N, Enosawa S, Ishii T, Thangavel R, Tashiro T, Okuyama T, Suzuki S: Human amniotic epithelial cells are promising transgene carriers for allogeneic cell transplantation into liver. J Hum Genet 2000, 45:171-176.

62. Takashima S, Ise H, Zhao P, Akaike T, Nikaido T: Human amniotic epithelial cells possess hepatocyte-like characteristics and functions. Cell Struct Funct 2004, 29:73-84.

63. Miki T, Marongiu F, Ellis EC, Dorko K, Mitamura K, Ranade A, Gramignoli R, Davila J, Strom SC: Production of hepatocyte-like cells from human amnion. Methods Mol Bio/ 2009, 481:155-168.

64. Manuelpillai U, Tchongue J, Lourensz D, Vaghjiani V, Samuel CS, Liu A, Williams ED, Sievert W: Transplantation of human amnion epithelial cells reduces hepatic fibrosis in immunocompetent $\mathrm{CCl}_{4}$-treated mice. Cell Transplant 2010, 19:1157-1168.

65. Nakajima T, Enosawa S, Mitani T, Li XK, Suzuki S, Amemiya H, Koiwai O, Sakuragawa N: Cytological examination of rat amniotic epithelial cells and cell transplantation to the liver. Cell Transplant 2001, 10:423-427.

66. Takahashi N, Enosawa S, Mitani T, Lu H, Suzuki S, Amemiya H, Amano T, Sakuragawa N: Transplantation of amniotic epithelial cells into fetal rat liver by in utero manipulation. Cell Transplant 2002, 11:443-449.

67. Marcus AJ, Coyne TM, Rauch J, Woodbury D, Black IB: Isolation, characterization, and differentiation of stem cells derived from the rat amniotic membrane. Differentiation 2008, 76:130-144.

68. Wei JP, Zhang TS, Kawa S, Aizawa T, Ota M, Akaike T, Kato K, Konishi I, Nikaido T: Human amnion-isolated cells normalize blood glucose in streptozotocininduced diabetic mice. Cell Transplant 2003, 12:545-552.

69. Hou Y, Huang Q, Liu T, Guo L: Human amnion epithelial cells can be induced to differentiate into functional insulin-producing cells. Acta Biochim Biophys Sin (Shanghai) 2008, 40:830-839

70. Szukiewicz D, Pyzlak M, Stangret A, Rongies W, Maslinska D: Decrease in expression of histamine $\mathrm{H} 2$ receptors by human amniotic epithelial cells during differentiation into pancreatic beta-like cells. Inflamm Res 2010, 59 Suppl 2:S205-207

71. Moodley Y, Ilancheran S, Samuel C, Vaghjiani V, Atienza D, Williams ED, Jenkin G, Wallace E, Trounson A, Manuelpillai U: Human amnion epithelial cell transplantation abrogates lung fibrosis and augments repair. Am J Respir Crit Care Med 2010, 182:643-651.

72. Moritoki Y, Ueno Y, Kanno N, Yamagiwa Y, Fukushima K, Gershwin ME, Shimosegawa T: Amniotic epithelial cell-derived cholangiocytes in experimental cholestatic ductal hyperplasia. Hepatol Res 2007, 37:286-294.

73. Fujimoto KL, Miki T, Liu L, Hashizume R, Strom SC, Wagner WR, Keller BB, Tobita $\mathrm{K}$ : Naive rat amnion-derived cell transplantation improved left ventricular function and reduced myocardial scar of postinfarcted heart. Cell Transplant 2009, 18:477-486.

74. Cargnoni A, Di Marcello M, Campagnol M, Nassuato C, Albertini A, Parolini O: Amniotic membrane patching promotes ischemic rat heart repair. Cell Transplant 2009, 18:1147-1159.

75. Tsuji H, Miyoshi S, Ikegami Y, Hida N, Asada H, Togashi I, Suzuki J, Satake M, Nakamizo H, Tanaka M, Mori T, Segawa K, Nishiyama N, Inoue J, Makino H, Miyado K, Ogawa S, Yoshimura Y, Umezawa A: Xenografted human amniotic membrane-derived mesenchymal stem cells are immunologically tolerated and transdifferentiated into cardiomyocytes. Circ Res 2010, 106:1613-1623.

76. Bailo M, Soncini M, Vertua E, Signoroni PB, Sanzone S, Lombardi G, Arienti D, Calamani F, Zatti D, Paul P, Albertini A, Zorzi F, Cavagnini A, Candotti F, Wengler
GS, Parolini O: Engraftment potential of human amnion and chorion cells derived from term placenta. Transplantation 2004, 78:1439-1448.

77. Hori J, Wang M, Kamiya K, Takahashi H, Sakuragawa N: Immunological characteristics of amniotic epithelium. Cornea 2006, 25:S53-58.

78. Kamiya K, Wang M, Uchida S, Amano S, Oshika T, Sakuragawa N, Hori J: Topical application of culture supernatant from human amniotic epithelial cells suppresses inflammatory reactions in cornea. Exp Eye Res 2005, 80:671-679.

79. Li H, Niederkorn JY, Neelam S, Mayhew E, Word RA, McCulley JP, Alizadeh H: Immunosuppressive factors secreted by human amniotic epithelial cells. Invest Ophthalmol Vis Sci 2005, 46:900-907.

80. Ueta M, Kweon MN, Sano Y, Sotozono C, Yamada J, Koizumi N, Kiyono H, Kinoshita S: Immunosuppressive properties of human amniotic membrane for mixed lymphocyte reaction. Clin Exp Immuno/ 2002, 129:464-470.

81. Wolbank S, Peterbauer A, Fahrner M, Hennerbichler S, van Griensven M, Stadle G, Redl H, Gabriel C: Dose-dependent immunomodulatory effect of human stem cells from amniotic membrane: a comparison with human mesenchymal stem cells from adipose tissue. Tissue Eng 2007, 13:1173-1183.

82. Lefebvre S, Adrian F, Moreau P, Gourand L, Dausset J, Berrih-Aknin S, Carosella ED, Paul P: Modulation of HLA-G expression in human thymic and amniotic epithelial cells. Hum Immuno/ 2000, 61:1095-1101.

83. Hammer A, Hutter H, Blaschitz A, Mahnert W, Hartmann M, Uchanska-Ziegler B, Ziegler A, Dohr G: Amnion epithelial cells, in contrast to trophoblast cells, express all classical HLA class I molecules together with HLA-G. Am J Reprod Immunol 1997, 37:161-171.

84. Houlihan JM, Biro PA, Harper HM, Jenkinson HJ, Holmes $\mathrm{CH}$ : The human amnion is a site of MHC class lb expression: evidence for the expression of HLA-E and HLA-G. J Immunol 1995, 154:5665-5674.

85. Rooney IA, Morgan BP: Protection of human amniotic epithelial cells (HAEC) from complement-mediated lysis: expression on the cells of three complement inhibitory membrane proteins. Immunology 1990, 71:308-311.

86. Rooney IA, Morgan BP: Characterization of the membrane attack complex inhibitory protein CD59 antigen on human amniotic cells and in amniotic fluid. Immunology 1992, 76:541-547.

87. Surendran S: Possible role of fas antigen (CD 95) in human amniotic epithelial cell death: an in vitro study. Cell Biol Int 2001, 25:485-488.

88. Kubo M, Sonoda Y, Muramatsu R, Usui M: Immunogenicity of human amniotic membrane in experimental xenotransplantation. Invest Ophthalmol Vis Sci 2001, 42:1539-1546.

89. Yeager AM, Singer HS, Buck JR, Matalon R, Brennan S, O'Toole SO, Moser HW: A therapeutic trial of amniotic epithelial cell implantation in patients with lysosomal storage diseases. Am J Med Genet 1985, 22:347-355.

90. Scaggiante B, Pineschi A, Sustersich M, Andolina M, Agosti E, Romeo D: Successful therapy of Niemann-Pick disease by implantation of human amniotic membrane. Transplantation 1987, 44:59-61.

91. Sakuragawa N, Yoshikawa H, Sasaki M: Amniotic tissue transplantation: clinical and biochemical evaluations for some lysosomal storage diseases. Brain Dev 1992, 14:7-11.

92. Akle CA, Adinolfi M, Welsh Kl, Leibowitz S, McColl I: Immunogenicity of human amniotic epithelial cells after transplantation into volunteers. Lancet 1981, 2:1003-1005

93. Miura M, Miura Y, Padilla-Nash HM, Molinolo AA, Fu B, Patel V, Seo BM, Sonoyama W, Zheng JJ, Baker CC, Chen W, Ried T, Shi S: Accumulated chromosomal instability in murine bone marrow mesenchymal stem cells leads to malignant transformation. Stem Cells 2006, 24:1095-1103.

94. Lane EL, Winkler C, Brundin P, Cenci MA: The impact of graft size on the development of dyskinesia following intrastriatal grafting of embryonic dopamine neurons in the rat. Neurobiol Dis 2006, 22:334-345.

95. Olanow CW, Freeman T, Kordower J: Transplantation of embryonic dopamine neurons for severe Parkinson's disease. N Engl J Med 2001, 345:146; author reply 147.

96. Nakatsuji N, Nakajima F, Tokunaga K: HLA-haplotype banking and iPS cells. Nat Biotechnol 2008, 26:739-740.

97. Serrano-Delgado VM, Novello-Garza B, Valdez-Martinez E: Ethical issues relating to the banking of umbilical cord blood in Mexico. BMC Med Ethics 2009, 10:12.

doi:10.1186/scrt66

Cite this article as: Miki T: Amnion-derived stem cells: in quest of clinical

applications. Stem Cell Research \& Therapy 2011, 2:25. 